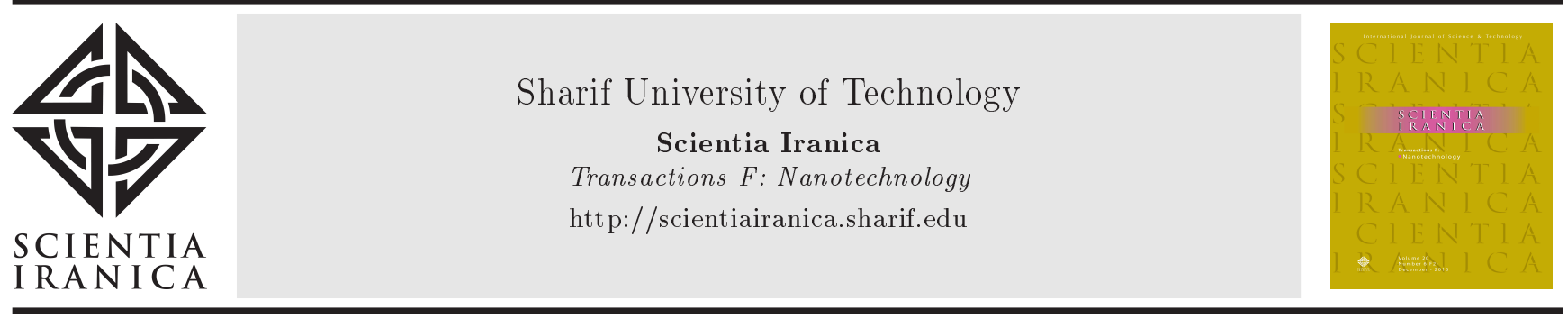

\title{
Design and synthesis of carbon nanotubes for adsorption utilities: An approach to direct preparation by mechanical milling at room temperature
}

\author{
M.H. Khazaei Feizabad ${ }^{a}$, G.R. Khayati ${ }^{b, *}$, and S. Pouresterabadi ${ }^{a}$ \\ a. Department of Nano Technology, Mineral Industries Research Center (MIRC), Shahid Bahonar University of Kerman, \\ 7618868366 Kerman, Iran. \\ b. Department of Material Science and Engineering, Shahid Bahonar University of Kerman, 7618868366 Kerman, Iran.
}

Received 18 February 2019; received in revised form 12 November 2019; accepted 26 September 2020

\section{KEYWORDS}

Carbon nanotubes; Mechanical milling; Amorphous catalyst; Crystalline catalyst; Hexane.

\begin{abstract}
The Carbon Nano-Tubes (CNTs) were produced by mechanical milling of hexane in the presence of two different catalysts, namely amorphous and crystalline $\mathrm{Fe}$, at Ar atmosphere. Raman spectroscopy, Fourier-transform infrared spectroscopy, transmission electron microscopy, high-resolution scanning electron microscopy, Brunauer Emmett Teller (BET), and thermal analysis were employed to characterize the CNTs. The results showed that the amorphous catalyst induced more structural defects in CNTs than the crystalline catalyst did. The ratio of single wall to multiwall CNTs in prepared samples was about 0.31 and 7.3 for the crystalline and amorphous catalysts, respectively. Moreover, the BET results confirmed the higher adsorption capacity of the sample prepared by the amorphous catalyst due to its higher structural defects.
\end{abstract}

(C) 2021 Sharif University of Technology. All rights reserved.

\section{Introduction}

Carbon nanotubes (CNTs) are a combination of rolled graphitic sheets in seamless cylindrical geometrical form. Since its discovery by Iijima (1991) [1], the study of this engineering material has been a hot topic for many researchers due to its unique chemical, electronic, thermal, and mechanical properties [2-6]. Such characteristics make CNTs a good candidate for advanced engineering applications in, e.g., field emission devices, scanning probe, nanoscale electronic devices, hydrogen storage, chemical sensors, and composite reinforcing materials [7-18]. To the best of our knowledge, CNTs have been prepared by various methods such as solar

*. Corresponding author. Tel.: +983432114053;

Fax: +983432114053

E-mail address: khayatireza@gmail.com (G.R. Khayati) production, electric arc discharge, laser ablation of a carbon target, chemical vapor deposition, electrochemical synthesis, pyrolysis of benzene in the presence of hydrogen, and reactive milling [19-29].

Compared to fossil fuels, using hydrogen with zero emission and carbon-free combustion products is highly preferred. Development of proton exchange membrane fuel cells plays a key role in replacement of hydrogen as a clean source of energy. In this regard, the evolution of on-board storage and release of hydrogen has administrative effects. There are various techniques for storage of hydrogen, e.g., liquefaction, compression at high pressure, and using metallic hydrides. Carbonaceous materials have outstanding characteristics as physisorption agents, making them a good candidate for use in the storage devices. For instance, they possess high gravimetric energy density due to the lower atomic mass of their constituents. Significant safety and energy efficiency are the other advantages of such compounds. Employment of carbonaceous 
structures for hydrogen storage and transportation has been the subject of many researches in the literature. CNTs with high specific surface and micropouros structure have excellent adsorbing potential, especially for hydrogen [30].

According to the literature, the existence of defects in the structure of CNTs significantly enhances their storage capacity for hydrogen. There are various approaches to the preparation of CNTs with a high density of defects, including oxidation of CNTs at high temperature, alkali-metal addition, oxidation using chemical agents $\left(\mathrm{HCl}\right.$ and $\left.\mathrm{HNO}_{3}\right)$ in the presence of an oxidizing agent, and mechanical milling [31].

In comparison with the arc discharge technique, the CNTs prepared through decomposition of carbon precursor (i.e., hydrocarbon) in the presence of an appropriate catalyst possess high defect density with, e.g., localized kinks or bends. Chemical vapor decomposition is one of the most common techniques of hydrocarbon decomposition for the preparation of CNTs. This technique has certain advantages including high yield, induction of a high density of defects in the prepared CNTs, and controllable growth. However, the prepared samples usually have closed ends and are tangled and long. As a consequence, their usage is limited when it comes to adsorbing and desorbing gas, in which CNTs with open tips are preferred. To resolve this shortcoming, various techniques have been developed including the use of scanning tunneling microscopy voltage or ultra-sound power, chemical treatment, and modification of the prepared samples to shorter and open-ended CNTs. Among such techniques, ball milling seems to be the cheapest and cleanest process without any need for further thermal and chemical treatment [32].

In the present paper, a novel approach to the preparation of CNTs is proposed through mechanical milling of hexane (i.e., carbon precursor) directly. Employing the milling process to exert mechanochemical changes, e.g., solid-state reactions and phase transformation, has been the subject of many researches $[34,35]$. Due to the mixing process and microstructure refinement during mechanical milling, the reaction rate dynamically increases as a function of milling time. Lowering the number of technical stages, removing the operational stages of employing solvents and stabilizing additives, reproductively, simplicity, mass production, easy handling, and removing any heating treatment are the main advantages of the proposed method for the preparation of CNTs.

Table 1 summarizes the researches carried on employing mechanical milling for the preparation and modification of CNTs. In the preparation approach, first, the graphitic precursor is transformed into ultraactive amorphous carbon and then, through hightemperature annealing, the amorphous phase is converted to CNTs. The latter stage of mechanical milling can also be taken to induce defects and enhance the surface area of the CNTs prepared though other techniques. However, in both cases, high temperature is required during the preparation of CNTs, which is the main drawback for this technique. However, our

Table 1. A summary of the researches carried out on mechanical milling for the preparation and modification of Carbon Nanotubes (CNTs).

\begin{tabular}{|c|c|c|c|c|c|c|}
\hline Ref. & $\begin{array}{l}\text { Guler } \\
\text { et al. [24] }\end{array}$ & $\begin{array}{l}\text { Chen } \\
\text { et al. [25] }\end{array}$ & $\begin{array}{l}\text { Chen } \\
\text { et al. [26] }\end{array}$ & $\begin{array}{l}\text { Liu } \\
\text { et al. [32] }\end{array}$ & $\begin{array}{c}\text { Pierard } \\
\text { et al. [33] }\end{array}$ & $\begin{array}{c}\text { Proposed } \\
\text { method }\end{array}$ \\
\hline Year & 2012 & 1999 & 2004 & 2003 & 2004 & - \\
\hline $\begin{array}{l}\text { Preparation } \\
\text { method }\end{array}$ & $\begin{array}{l}\text { Mechano } \\
\text {-thermal } \\
\text { process }\end{array}$ & $\begin{array}{l}\text { Mechano } \\
\text {-thermal } \\
\text { process }\end{array}$ & $\begin{array}{l}\text { Mechano } \\
\text {-thermal } \\
\text { process }\end{array}$ & $\begin{array}{l}\text { Chemical } \\
\text { vapor } \\
\text { deposition }\end{array}$ & $\begin{array}{l}\text { Chemical } \\
\text { vapor } \\
\text { deposition }\end{array}$ & $\begin{array}{l}\text { Mechanical } \\
\text { milling }\end{array}$ \\
\hline Precursor & Graphite & Graphite & Graphite & Acetylene & Methane & Hexane \\
\hline $\begin{array}{l}\text { Milling } \\
\text { effect }\end{array}$ & $\begin{array}{l}\text { Ultra-active } \\
\text { amorphous } \\
\text { carbon }\end{array}$ & $\begin{array}{l}\text { Ultra-active } \\
\text { amorphous } \\
\text { carbon }\end{array}$ & $\begin{array}{l}\text { Ultra-active } \\
\text { amorphous } \\
\text { carbon }\end{array}$ & $\begin{array}{l}\text { Increase } \\
\text { in the } \\
\text { surface area }\end{array}$ & $\begin{array}{l}\text { Increase } \\
\text { in the } \\
\text { surface area }\end{array}$ & $\begin{array}{l}\text { Synthesis } \\
\text { and increase } \\
\text { in the } \\
\text { surface area }\end{array}$ \\
\hline $\begin{array}{l}\text { Preparation } \\
\text { temperature }\left({ }^{\circ} \mathrm{C}\right)\end{array}$ & $1600-1800$ & 1400 & 1400 & 700 & 1000 & $\begin{array}{l}\text { Room } \\
\text { temperature }\end{array}$ \\
\hline
\end{tabular}


proposed approach provides the possibility of CNT preparation at room temperature with significant defects in structure. The main contribution of the present study are:

- Direct synthesis of CNTs by mechanical alloying without any further heat treatment;

- Preparation of CNTs with a high density of defects as adsorbent agents;

- Using Fe and $\mathrm{Fe}_{0.7} \mathrm{Nb}_{0.1} \mathrm{Zr}_{0.1} \mathrm{Ti}_{0.1}$ amorphous alloy as catalysts in the preparation of CNTs through mechanical milling.

\section{Materials and method}

In this study, the CNTs were prepared by mechanical milling of $10 \mathrm{~mL}$ hexane $\left(\mathrm{C}_{6} \mathrm{H}_{14}\right.$; Merck; 98.5\%) in the presence of 10 gr Fe or $\mathrm{Fe}_{0.7} \mathrm{Nb}_{0.1} \mathrm{Zr}_{0.1} \mathrm{Ti}_{0.1}$ powder as catalyst. Fe (Merck, 99\%, $10 \mu \mathrm{m}$ ), Nb (Alfa Aesar, 99.8\%,<44 $\mu \mathrm{m}$ ), Zr (Merck, 99.8\%, $50 \mu \mathrm{m}$ ), and $\mathrm{Ti}$ (Alfa Aesar, 99\%, <44 $\mu \mathrm{m}$ ) were used as raw materials. The precursor and the catalyst were subject to severe mechanical milling. Table 2 summarizes the details of the milling process.

To avoid oxidation of the precursor and the catalysts, the milling was carried out at Ar atmosphere. Also, the evaporation of carbon precursor was compensated by the addition of $5 \mathrm{~mL}$ hexane to the vial after $20 \mathrm{~h}$ of milling. Purification of CNTs was carried out through the reflux technique to eliminate the catalyst particles. In this step, 8 gr of the asmilled sample was refluxed in $2 \mathrm{~L} \mathrm{H}_{2} \mathrm{SO}_{4}(6 \mathrm{M})$ for $6 \mathrm{~h}$ at the temperature of $80^{\circ} \mathrm{C}$. The solution was then centrifuged at $4000 \mathrm{rpm}$ for $15 \mathrm{~min}$ and washed 3 times by twice-distilled water. Finally, the products were dried at $50^{\circ} \mathrm{C}$ for $30 \mathrm{~min}$. Structural and phase changes were studied through X-Ray Diffraction (XRD) by using an EQuniox 3000 powder diffractometer with $\mathrm{Cu}$ target. To investigate the morphology and size of the CNTs, High-Resolution Scanning Electron Microscopy (HRSEM) was done by a Hitachi S-4160 and Transmission Electron Microscopy (TEM) was performed by a Philips CM30. Determination of the functional groups was carried out by Fourier Transform Infrared Spectroscopy (FTIR) using a TENSOR 27 within the range of $4000-400 \mathrm{~cm}^{-1}$. Qualification of the products was carried out by Raman spectroscopy (Takram P50C0R10) with monochromatic light at $532.8 \mathrm{~nm}$ of the $\mathrm{Nd}$ :YAG laser as the excitation source within the range of $100-4400 \mathrm{~cm}^{-1}$. Thermogravimetry (German NETZSCH-STA 409C thermal analyzer) was performed by selection of $7 \pm 0.5 \mathrm{mg}$ of each sample to study the purity of products in the air at the heating rate of $10^{\circ} \mathrm{C} / \mathrm{min}$ within the range of 30 to $800^{\circ} \mathrm{C}$. The reproducibility of results was confirmed by repetition of TG curves for three times. Nitrogen adsorption measurements at $77 \mathrm{~K}$ were carried out using a volumetric adsorption apparatus (Belsrp Mini ii, Bel Company, Japan). The amount of nitrogen adsorption for each measured point was set to $3 \mathrm{cc}$ at $273 \mathrm{~K}$ and $760 \mathrm{mmHg}$.

\section{Results and discussion}

\subsection{Synthesis of CNTs}

Figure 1 illustrates the FTIR spectra for the prepared samples in the presence of $\mathrm{Fe}$ or $\mathrm{Fe}_{0.7} \mathrm{Nb}_{0.1} \mathrm{Zr}_{0.1} \mathrm{Ti}_{0.1}$ as a catalyst. As shown, the peaks at about $2934 \mathrm{~cm}^{-1}$, $2850 \mathrm{~cm}^{-1}$, and $1636 \mathrm{~cm}^{-1}$ are attributed to $\mathrm{C}-\mathrm{H}$ stretching, O-H stretching, and $\mathrm{C}-\mathrm{H}$ bending, respec-

Table 2. Practical parameters of milling and the details of planetary ball mill.

\begin{tabular}{ll}
\hline Characteristics & Value \\
\hline Vial rotation speed (rpm) & 350 \\
Disc rotation speed (rpm) & 250 \\
Disc diameter (mm) & 350 \\
Vial diameter (mm) & 90 \\
Vial material & Hardened chromium steel \\
Vial capacity (mL) & 150 \\
Ball material & Hardened carbon steel \\
Ball diameter (mm) & 15 \\
Ball to powder weight ratio & $20: 1$ \\
Milling time (h) & 100 \\
Rest time & 15 min for every 30 min of milling \\
Milling type & Wet \\
Milling atmosphere & Ar \\
Initial powder mass (g) & 10 \\
\hline
\end{tabular}




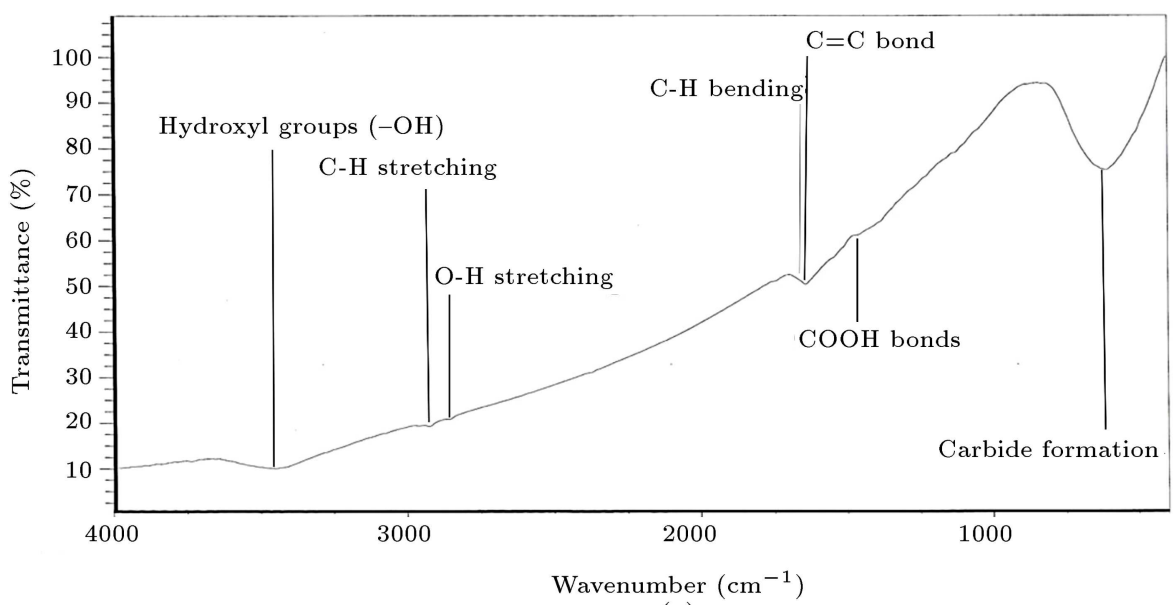

(a)

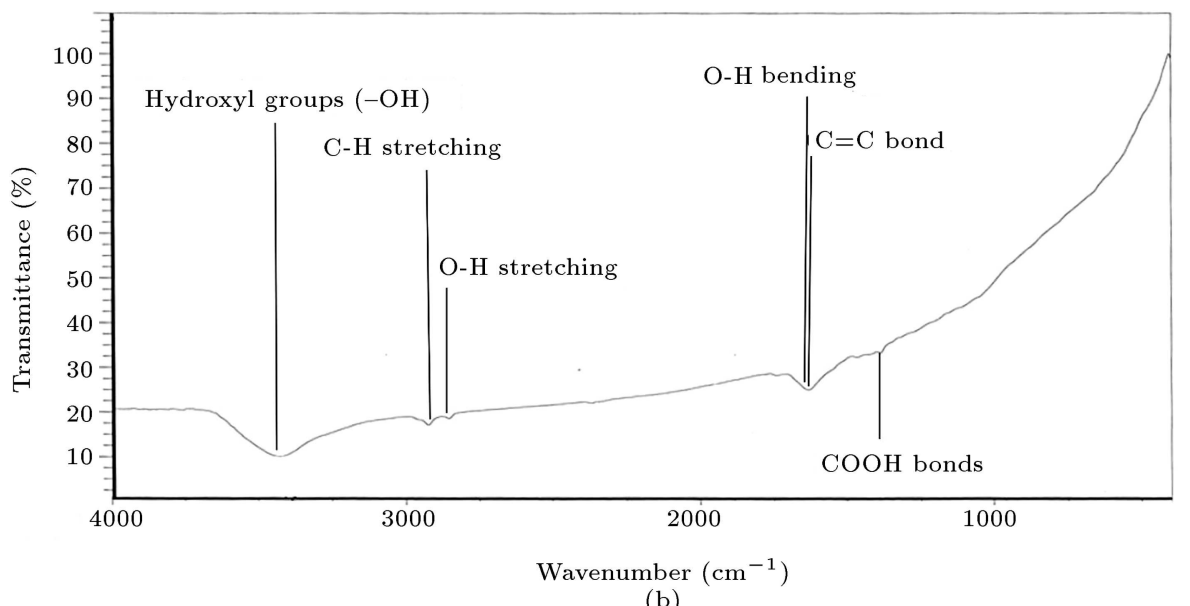

Figure 1. Fourier Transform Infrared Spectrum (FTIR) spectra of the as-prepared samples after $100 \mathrm{~h}$ of milling before purification in the presence of (a) Fe and (b) $\mathrm{Fe}_{0.7} \mathrm{Nb}_{0.1} \mathrm{Zr}_{0.1} \mathrm{Ti}_{0.1}$ catalysts.

tively. The peaks observed at $2934 \mathrm{~cm}^{-1}$ due to C$\mathrm{H}$ aliphatic bond and $1628 \mathrm{~cm}^{-1}$ due to $\mathrm{C}=\mathrm{C}$ bond confirm the formation of CNTs. The evolution of weak peaks in the range of $1850-2000 \mathrm{~cm}^{-1}$ and $1750-1845$ $\mathrm{cm}^{-1}$ can be related to the $\mathrm{C}=\mathrm{O}$ bonds while the peak at $1270 \mathrm{~cm}^{-1}$ is a sign of $\mathrm{COOH}$ bonds formation [36]. Moreover, the presence of a peak at $609 \mathrm{~cm}^{-1}$ in Figure 1(a) confirms the formation of carbides in the sample prepared by using the Fe catalyst. Consequently, the induced energy by mechanical milling is able to provide the required energy for decomposition of hexane to $\mathrm{C}$ and $\mathrm{H}[24,37,38]$. In other words, prolonged milling (up to $100 \mathrm{~h}$ ) provides the possibility of nucleation of free carbon as CNTs on the particles of catalyst.

The TEM images of the as-prepared samples after $100 \mathrm{~h}$ of milling in the presence of various catalysts are shown in Figure 2. As illustrated, in both samples, the catalyst particles act as nucleation sites for the formation of CNTs. Also, encapsulation of the catalyst particles is an obvious phenomenon in both cases.

To show the dissolution of $\mathrm{C}$ species in the cata- lyst particles, the shifts in the Bragg angles are compared for (110) peaks of unmilled and milled Fe powder in the presence of hexane after $100 \mathrm{~h}$ of milling (Figure $3(\mathrm{a}))$. As shown, the mechanical milling decreases the intensity of peak as well as peak broadening due to grain refining and induction of strain in $\mathrm{Fe}$ powder. On the other hand, the dissolution of $\mathrm{C}$ species in the milled sample shifted the peak to lower angles. The presence of $\mathrm{Fe}_{3} \mathrm{C}$ and $\mathrm{Fe}_{5} \mathrm{C}_{2}$ is confirmed by the XRD results for this sample (Figure $3(\mathrm{a})$ ). It is necessary to note that the possibility of carbide phase formation increases after prolonged milling on the sample prepared by using Fe as catalyst. A similar observation in another study [39] confirms the transformation of $\mathrm{Fe}$ to $\mathrm{Fe}_{3} \mathrm{C}$ at the first step and the growth of CNTs on cementite as an active site for nucleation at the next step. In another research [40], it has been emphasized that the stable carbide nanocrystals can act as the roots for the formation of nanotube.

To confirm the dissolution of $\mathrm{C}$ species in the $\mathrm{Fe}$ or $\mathrm{Fe}_{0.7} \mathrm{Nb}_{0.1} \mathrm{Zr}_{0.1} \mathrm{Ti}_{0.1}$ catalyst, (110) peaks of $\mathrm{Fe}$ as matrix are compared in samples prepared with and 


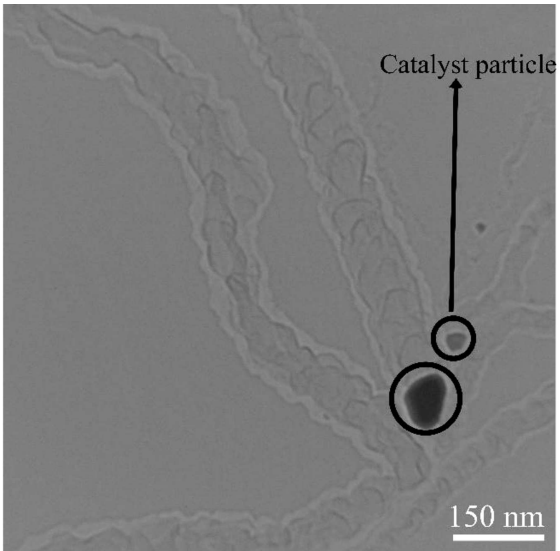

(a)

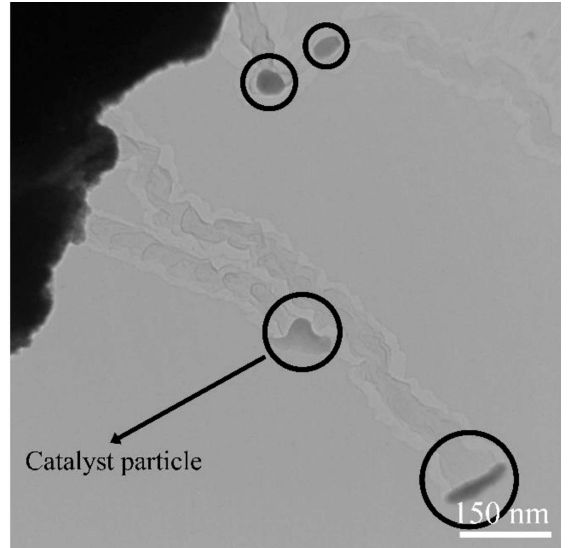

(b)

Figure 2. Transmission Electron Microscopy (TEM) images of the as-prepared samples after $100 \mathrm{~h}$ of milling in the presence of (a) Fe and (b) $\mathrm{Fe}_{0.7} \mathrm{Nb}_{0.1} \mathrm{Zr}_{0.1} \mathrm{Ti}_{0.1}$ catalysts.

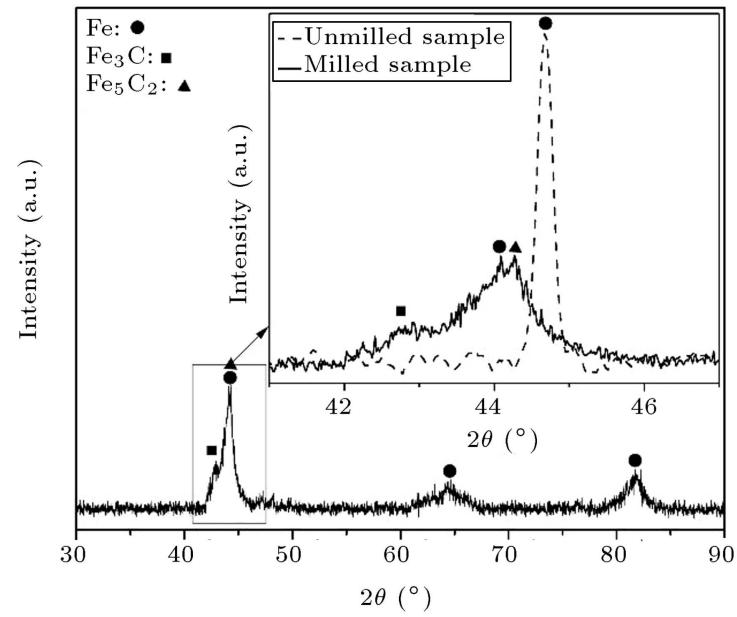

(a)

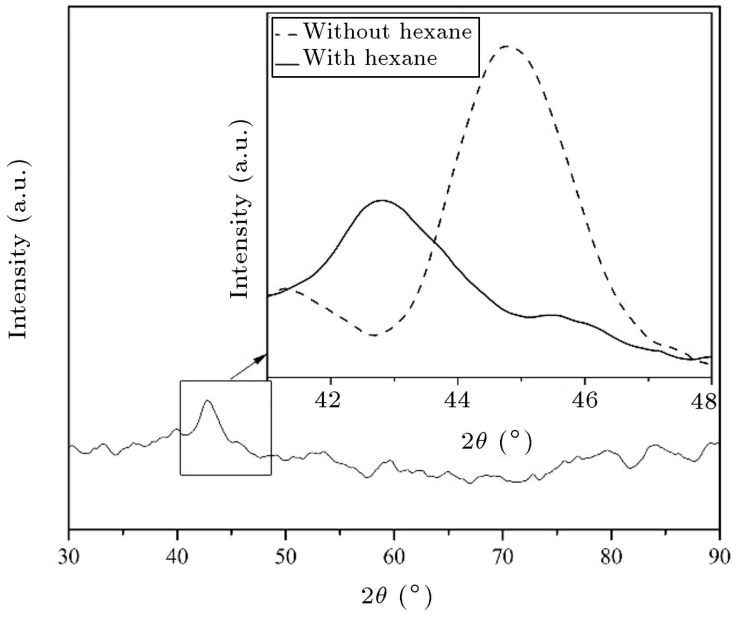

(b)

Figure 3. Comparison of the shape and position of Fe (110) peaks for (a) the unmilled sample of Fe powder and milled sample in the presence of Fe catalyst and (b) the milled samples of $\mathrm{Fe}_{0.7} \mathrm{Nb}_{0.1} \mathrm{Zr}_{0.1} \mathrm{Ti}_{0.1}$ with and without hexane after $100 \mathrm{~h}$.

without hexane after $100 \mathrm{~h}$ of milling (Figure 3(b)). As shown, increasing the milling time for both samples significantly decreased the sharpness of the main peak due to the formation of an amorphous alloy. Also, the obvious shift of the main peak to lower angles can be related to the dissolution of $\mathrm{C}$ species in the catalyst from hexane.

The growth mechanism of CNTs has been a controversial issue since the time of its discovery. Various mechanisms have been proposed by considering the reaction condition and post-deposition product characterization. Since in the present study, the catalyst particles were substrate-free, hexane was decomposed on the surface of catalyst particles to $\mathrm{H}$ and $\mathrm{C}$ species. $\mathrm{H}_{2}$ flied away and $\mathrm{C}$ was dissolved into the catalyst particles. The dissolved carbon was diffused towards the other zone of the catalyst due to the concentration gradient. Accordingly, the concentration gradient encourages the $\mathrm{C}$ species to nucleate as CNTs at the other side of the catalyst $[2,41]$.

Moreover, in comparison with the $\mathrm{Fe}_{5} \mathrm{C}_{2}$ phase, all pathways on the surface of $\mathrm{Fe}_{3} \mathrm{C}$ pose significantly small barriers for the migration of $\mathrm{C}$ and formation of $\mathrm{C}-\mathrm{C}$ bond, i.e. $\mathrm{C}$ polymerization. The kinetic and thermodynamic aspects of the higher catalytic activity of $\mathrm{Fe}_{3} \mathrm{C}$ than $\mathrm{Fe}_{5} \mathrm{C}_{2}$ were demonstrated by Mazzucco et al. [39]. The dissolution of excess amount of $\mathrm{C}$ in catalyst particles during the milling ceases the CNT growth by poisoning [42] or phase transformation of $\mathrm{Fe}_{3} \mathrm{C}$ to $\mathrm{Fe}_{5} \mathrm{C}_{2}$ [39].

The XRD results for the sample prepared by using $\mathrm{Fe}_{0.7} \mathrm{Nb}_{0.1} \mathrm{Zr}_{0.1} \mathrm{Ti}_{0.1}$ catalyst (Figure $3(\mathrm{~b})$ ) confirm the formation of amorphous phase and the ability of the catalyst for CNT formation. In this sample, the 


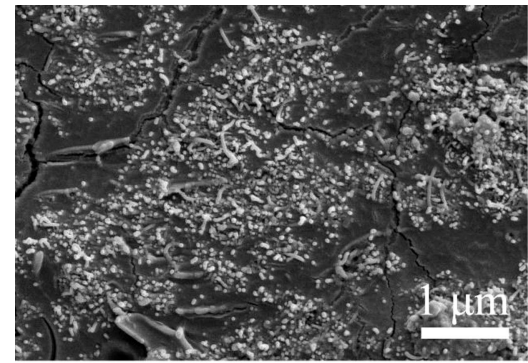

(a)

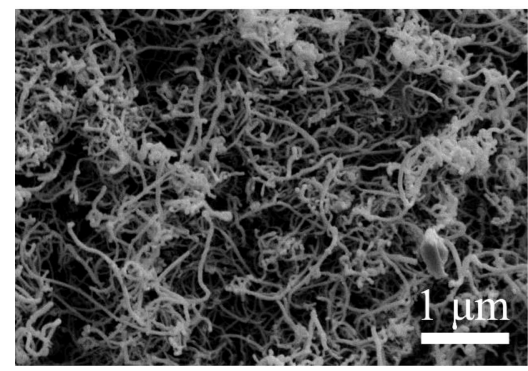

(c)

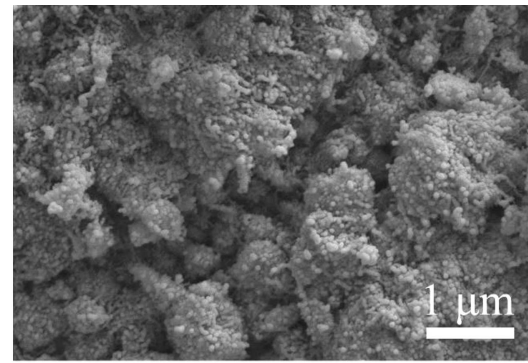

(b)

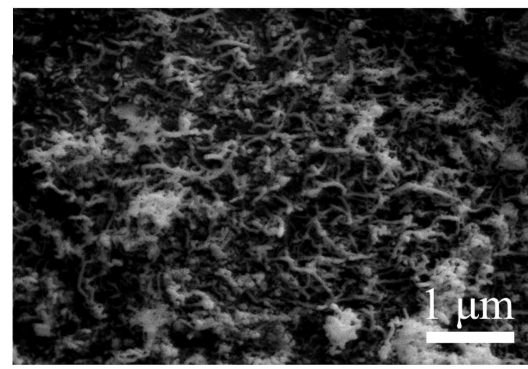

(d)

Figure 4. High-Resolution Scanning Electron Microscopy (HRSEM) images of the prepared samples in the presence of (a) Fe catalyst before purification, (b) Fe catalyst after purification, (c) $\mathrm{Fe}_{0.7} \mathrm{Nb}_{0.1} \mathrm{Zr}_{0.1} \mathrm{Ti}_{0.1}$ catalyst before purification, and (d) $\mathrm{Fe}_{0.7} \mathrm{Nb}_{0.1} \mathrm{Zr}_{0.1} \mathrm{Ti}_{0.1}$ catalyst after purification.

dissolution of alloy elements ( $\mathrm{Nb}, \mathrm{Zr}$, and $\mathrm{Ti}$ ) in Fe matrix facilitates the diffusion of carbon in the amorphous catalyst.

HRSEM images of purified samples in Figure 4(b) and (d) confirm the formation of tubular products after $100 \mathrm{~h}$ of milling in both cases. Due to the formation of higher Multi-Wall Carbon Nano-Tubes (MWCNTs) in the presence of Fe as well as the higher amount of amorphous carbon in the presence of $\mathrm{Fe}_{0.7} \mathrm{Nb}_{0.1} \mathrm{Zr}_{0.1} \mathrm{Ti}_{0.1}$, the tubular morphology is more obvious in the presence of Fe catalyst (compare Figure 4(a) and (b)) with (Figure $4(\mathrm{c})$ and $(\mathrm{d}))$. Similar results are confirmed by TG and Raman analyses given in Figures 5 and 6 .

\subsection{Quality determination of CNTs}

Raman spectroscopy is a powerful technique for the characterization of both CNT types, namely SingleWall Carbon Nano-Tubes (SWCNTs) and MWCNTs. Generally, there are three types of Raman spectra during CNTs characterization, namely Radial Breathing Mode (RBM), first-order spectra, and second-order spectra. RBM is an out-of-plane phonon mode, due to the coherent movement of $\mathrm{C}$ atoms in the radial direction, considered as the main sign of SWCNTs. The first-order spectra evolve in all graphite-like materials (such as MWCNTs) with a strong peak at around $1580 \mathrm{~cm}^{-1}(\mathrm{G})$, named the high-frequency E2g. Additionally, bands around $1350 \mathrm{~cm}^{-1}$ (D) and $1620 \mathrm{~cm}^{-1}$ (D') have been reported in the characterization of CNTs for the first-order type of Raman spectra. The characterization peaks in the secondorder Raman spectra have been observed at $2450 \mathrm{~cm}^{-1}$,

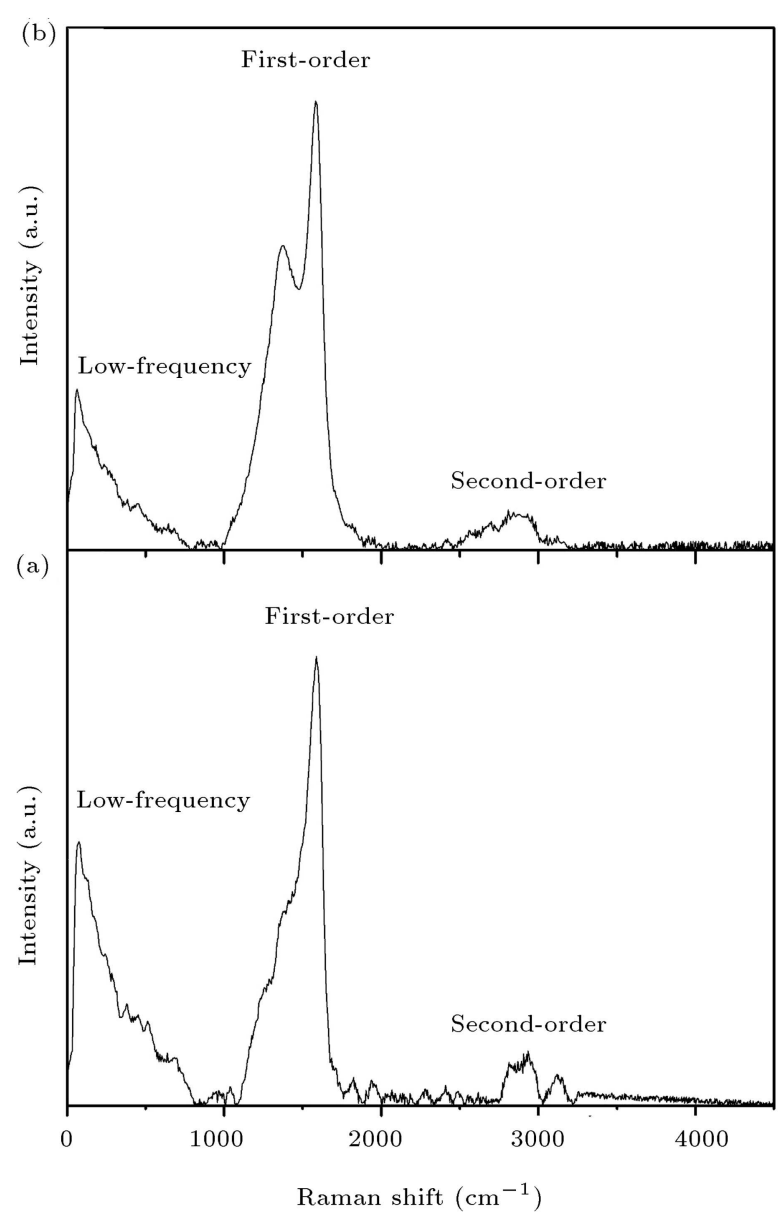

Figure 5. Normalization of Raman spectra by considering $\mathrm{G}$ band as the criterion for the samples prepared in the presence of (a) Fe and (b) $\mathrm{Fe}_{0.7} \mathrm{Nb}_{0.1} \mathrm{Zr}_{0.1} \mathrm{Ti}_{0.1}$ catalysts. 

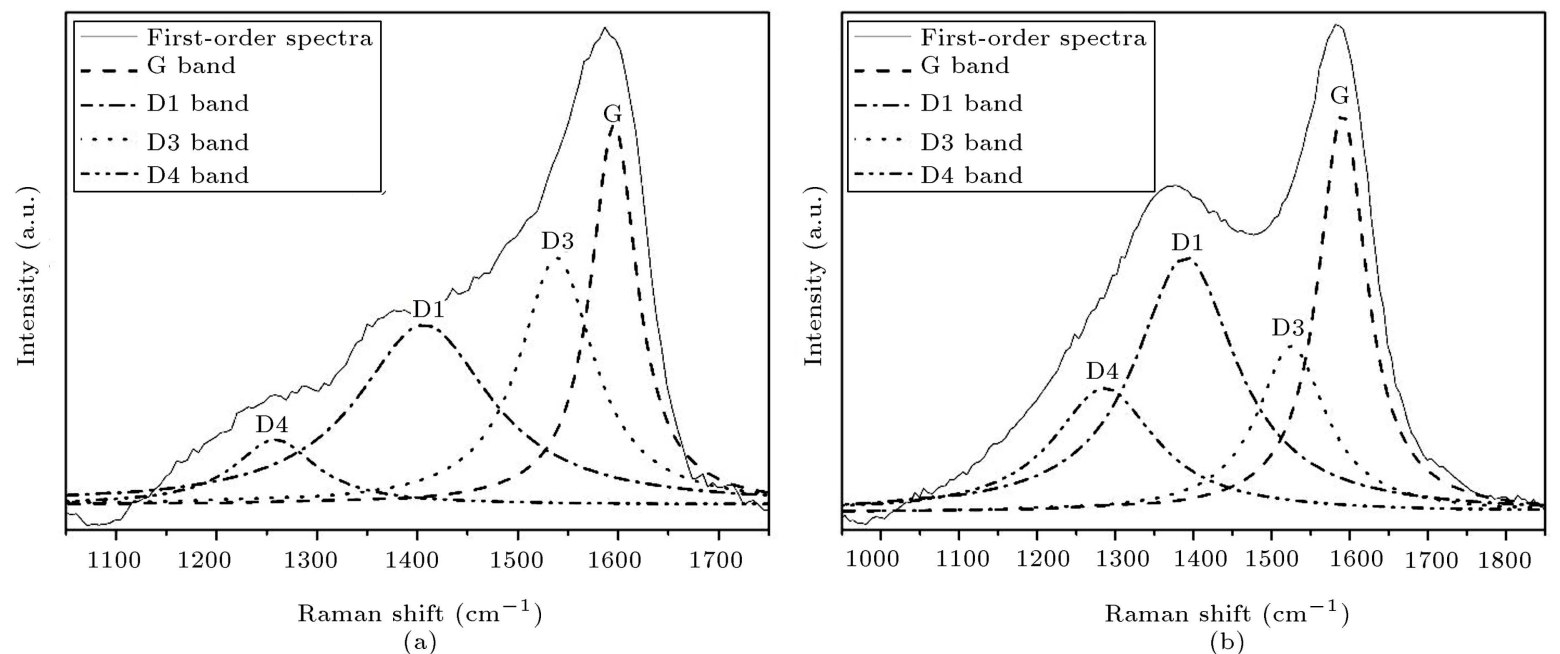

Figure 6. Deconvolution of the Raman overlapping peaks for the sample prepared in the presence of (a) Fe and (b) $\mathrm{Fe}_{0.7} \mathrm{Nb}_{0.1} \mathrm{Zr}_{0.1} \mathrm{Ti}_{0.1}$ catalysts.

$2705 \mathrm{~cm}^{-1}\left(\mathrm{G}^{\prime}\right), 2945 \mathrm{~cm}^{-1}(\mathrm{D}+\mathrm{G}), 3176 \mathrm{~cm}^{-1}(2 \mathrm{G})$, and $3244 \mathrm{~cm}^{-1}\left(2 \mathrm{D}^{\prime}\right)$ [43].

As shown in Figure 5(a) and (b), the formation of CNTs is confirmed in both samples. Accordingly, the evolution of a peak at a frequency lower than $200 \mathrm{~cm}^{-1}$ can be related to the symmetric RBM. It is noteworthy that the frequency of this peak is only a function of tube diameter (inversely proportional) and RBM cannot be usually detected in SWCNTs with diameters higher than $2 \mathrm{~nm}$ [44]. However, the outer sheet curvature of MWCNTs is similar to that of graphene and the inner sheet is similar to that of SWCNTs [44]. The presence of RBM in high-quality MWCNTs composed of relatively small innermost tubes is possible, as reported in the literature [45]. The broader lowerfrequency region than the bands arising from RBM (about FWHM 3-5 $\mathrm{cm}^{-1}$ for MWCNTs and 5-10 $\mathrm{cm}^{-1}$ for SWCNTs) in this study can be related to the structural defects as well as encapsulated catalyst particles in CNTs $[44,46]$. As shown, the first-order peaks of both samples overlap due to the formation of carbon base impurities and imperfections $[47,48]$. The Lorentzian function was employed to deconvolute the overlapping peaks and determine the type of every band (Figure 6) [43].

The ideal CNTs show only one first-order band ( $G$ band) due to the lattice vibration of the ideal graphitic network with E2g symmetry around $1580 \mathrm{~cm}^{-1}$. However, in the presence of defects in CNTs network, additional first-order bands ( $D$ or defect bands) are observed due to deviation from the ideal network. The relatively high intensity of the D-type peak belongs to D1 around $1360 \mathrm{~cm}^{-1}$, corresponding to the vibration of the graphitic lattice with A1g symmetry. D2 is another first-order band about $1620 \mathrm{~cm}^{-1}$ revealed as a shoulder on $G$ band. Similar to the G band, D2 is a consequence of graphitic lattice mode vibration with E2g symmetry. The intensity of defect bands (D1 and D2) is enhanced by increasing the wavelength of excitation as a consequence of resonance effects. The D1 band may stem from the defects in CNTs structure, e.g., the end of CNTs or foreign atoms in CNTs structure. On the other hand, D2 is a consequence of lattice vibration of graphene layers on the surface of the graphitic crystal [48].

The peak with relatively high intensity among the local maximum peaks around $1500 \mathrm{~cm}^{-1}$ belongs to the other type of bands, namely D3. This band may originate from the presence of amorphous carbon, i.e. organic molecules, fragments, or functional groups [48]. Another peak around $1350 \mathrm{~cm}^{-1}$, which exhibits a shoulder at $1200 \mathrm{~cm}^{-1}$ (named D4 band), is related to the $\mathrm{C}-\mathrm{C}$ and $\mathrm{C}=\mathrm{C}$ stretching vibrations of the polyene-like structure as well as sp2-sp3 bands. In summary, D1, D2, and D4 indicate the presence of defects and imperfections in the graphitic lattice. On the other hand, D3 band belongs to the amorphous carbon constituents [48]. As shown in Figure 6, with the exception of the D2 band, all other types of Raman peaks are observed in both samples.

Dresselhaus et al. [49] employed the ratio of $I_{D 1}$ to $I_{G}$ as a criterion for determining CNT quality. $I_{D 1} / I_{G}$ ratios lower than 0.45 belong to high quality CNTs. Figure 6 shows the deconvolution of the overlapping Raman peaks for the two samples. According to Figure $6(\mathrm{a})$, the sample prepared by $\mathrm{Fe}_{0.7} \mathrm{Nb}_{0.1} \mathrm{Zr}_{0.1} \mathrm{Ti}_{0.1}$ shows higher $I_{D 1} / I_{G}(0.62)$ than the other one with an $I_{D 1} / I_{G}$ ration equal to 0.45 (Figure $6(\mathrm{~b})$ ). As shown in the XRD spectra for both samples (Figure 3 ), prolonging milling beyond $100 \mathrm{~h}$ caused the amorphization of $\mathrm{Fe}_{0.7} \mathrm{Nb}_{0.1} \mathrm{Zr}_{0.1} \mathrm{Ti}_{0.1}$, while the other sample was still in the crystalline phase. The amorphization 


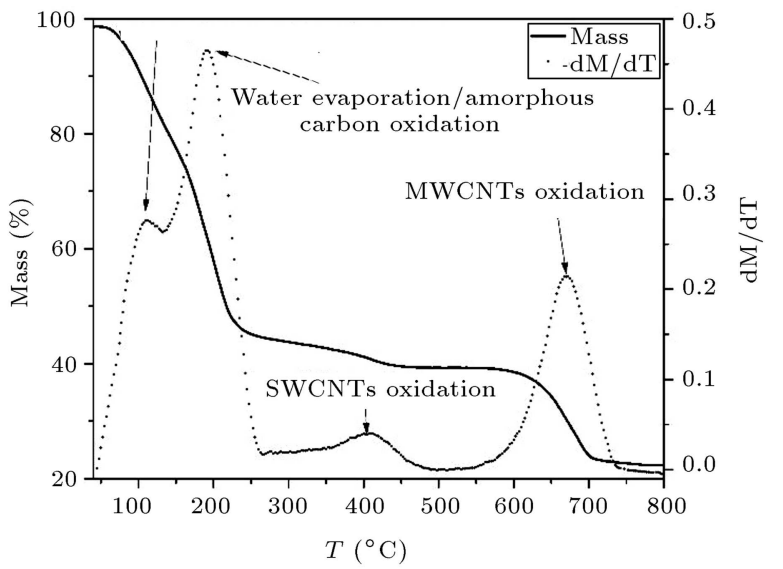

(a)

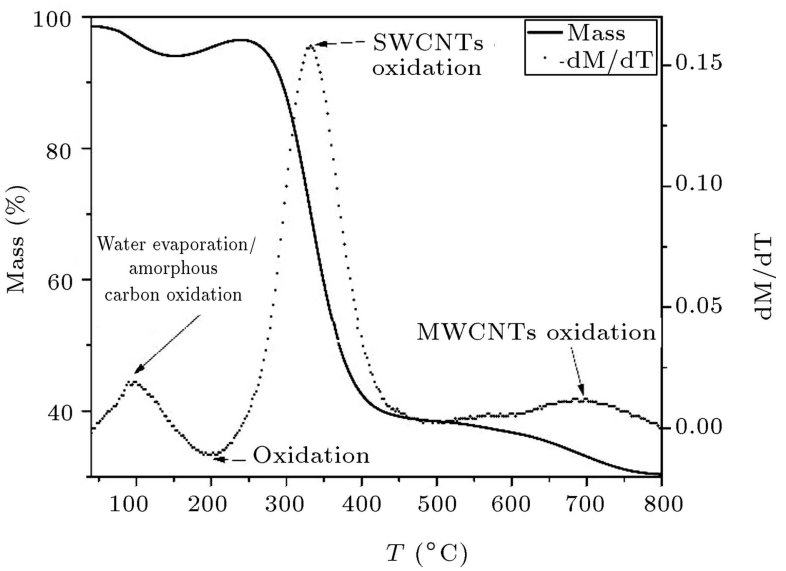

(b)

Figure 7. Weight loss and its derivatives as a function of temperature for the samples prepared in the presence of (a) Fe and (b) $\mathrm{Fe}_{0.7} \mathrm{Nb}_{0.1} \mathrm{Zr}_{0.1} \mathrm{Ti}_{0.1}$ catalysts.

mechanism of these alloys has been investigated in the literature [37,50-52]. It can be concluded that the presence of a catalyst in the amorphous phase leads to the lower quality of the prepared CNTs due to the lower crystallinity of the catalyst as well as enhanced possibility of defect formation in the CNTs structure.

On the one hand, the formation of amorphous Fe-based alloy (i.e., $\mathrm{Fe}_{0.7} \mathrm{Nb}_{0.1} \mathrm{Zr}_{0.1} \mathrm{Ti}_{0.1}$ ) is easier than the formation of amorphous phase during the milling of pure Fe [38] and, on the other hand, the metallic catalyst acts as a substrate for the nucleation of CNTs [42]. Consequently, higher crystallinity and better shape of $\mathrm{Fe}$ than those of $\mathrm{Fe}_{0.7} \mathrm{Nb}_{0.1} \mathrm{Zr}_{0.1} \mathrm{Ti}_{0.1}$ in the growth of CNTs facilitate the formation of graphite layers as a consequence of the dynamic interaction between the carbon and Fe catalyst.

\subsection{Purity determination of CNTs}

According to the literature, MWCNTs with high crystallinity are more oxidation-resistant than the other carbon allotropes, i.e., $C_{60}$, diamond, graphite, and soot [44]. It should be noted that some other factors, e.g., the number of walls in MWCNTs, the type and amount of residual catalyst, the imperfection within the walls, and the presence of other carbon allotropes, affect the MWCNTs oxidation behavior. It is well established that the oxidation temperature of carbon allotropes can range from low to high with amorphous carbons, SWCNTs, MWCNTs, and graphitic particles [44]. However, the oxidation temperature of various carbon allotropes has not been well defined distinctively. Typically, the oxidation temperature for MWCNTs has been reported in the range of $400-750^{\circ} \mathrm{C}$ [44], while the amorphous carbon species $\left(200-300^{\circ} \mathrm{C}\right)$ and SWCNTs $\left(350-500^{\circ} \mathrm{C}\right)$ have lower oxidation temperatures [44].

To determine the purification of products using TG curves, the mass changes during the heating must be exaggerated as oxidation peaks by determining mass derivation versus temperature $(\mathrm{dM} / \mathrm{dT})$. Since every oxidation peak is related to the oxidation of one or more product species, it is possible to use the number of peaks as a threshold for the purity of a product. Figure 7 shows the weight loss and its derivative as a function of temperature for both samples. As the TG curve in Figure 7(a) indicates, the prepared sample in the presence of $\mathrm{Fe}$ experiences a severe weight loss (about 55 wt.\%) up to the temperature of $270^{\circ} \mathrm{C}$ as an overlap. Further analysis of the $\mathrm{dM} / \mathrm{dT}$ curve confirms the presence of two peaks in the range of 50 to $270^{\circ} \mathrm{C}$ due to water evaporation and amorphous carbon oxidation [44]. The next weight loss is situated between $270^{\circ} \mathrm{C}$ to $490^{\circ} \mathrm{C}$, which can be related to the oxidation of SWCNTs. The last weight loss in the range $550^{\circ} \mathrm{C}$ to $740^{\circ} \mathrm{C}$ is associated with the oxidation of MWCNTs. In summary, the TG diagram confirms 55.3, 5.3, and $16.8 \%$ weight loss in this sample due to water evaporation/amorphous carbon oxidation, SWCNTs oxidation, and MWCNTs oxidation, respectively. The balanced weight $(22.6 \mathrm{wt} . \%)$ is due to the residual catalyst. It can be seen that the ratio of SWCNTs to MWCNTs in this sample is about 0.31 .

Analysis of the $\mathrm{dM} / \mathrm{dT}$ curve in Figure $7(\mathrm{~b})$ reveals that the sample prepared in the presence of $\mathrm{Fe}_{0.7} \mathrm{Nb}_{0.1} \mathrm{Zr}_{0.1} \mathrm{Ti}_{0.1}$ undergoes a weight loss peak up to the temperature of $150^{\circ} \mathrm{C}$ due to water evaporation/oxidation of amorphous carbon. A small increase in the weight is observed in the TG diagram between $150^{\circ} \mathrm{C}$ and $240^{\circ} \mathrm{C}$ as an overlap (about $0.7 \mathrm{wt} . \%$ ). These peaks can be related to the oxidation of trace residual metallic or unalloyed metallic catalyst during the heating. Within the range of $240^{\circ} \mathrm{C}$ to $490^{\circ} \mathrm{C}$, a drastic weight loss is observed as a consequence of SWCNTs oxidation. The last weight loss occurs in the range of $490^{\circ} \mathrm{C}$ to $800^{\circ} \mathrm{C}$ as a broad peak due to the oxidation of MWCNTs. In summary, the TG 
Table 3. Comparison of the initiation and oxidation temperatures of the prepared samples in the presence of Fe and $\mathrm{Fe}_{0.7} \mathrm{Nb}_{0.1} \mathrm{Zr}_{0.1} \mathrm{Ti}_{0.1}$ as catalysts.

\begin{tabular}{cccc}
\hline Type of catalyst & CNTs type & $\begin{array}{c}\text { Initiation } \\
\text { temperature } \\
\left({ }^{\circ} \mathbf{C}\right)\end{array}$ & $\begin{array}{c}\text { Oxidation } \\
\text { temperature } \\
\left({ }^{\circ} \mathbf{C}\right)\end{array}$ \\
\hline \multirow{2}{*}{$\mathrm{Fe}$} & SWCNTs & 270 & 410 \\
& MWCNTs & 550 & 670 \\
& & & \\
$\mathrm{Fe}_{0.7} \mathrm{Nb}_{0.1} \mathrm{Zr}_{0.1} \mathrm{Ti}_{0.1}$ & SWCNTs & 240 & 330 \\
& MWCNTs & 490 & 680 \\
\hline
\end{tabular}

diagram of the sample prepared in the presence of $\mathrm{Fe}_{0.7} \mathrm{Nb}_{0.1} \mathrm{Zr}_{0.1} \mathrm{Ti}_{0.1}$ confirms 1.5, 14.6, and 2 wt.\% loss as a consequence of water evaporation/amorphous carbon oxidation, SWCNTs oxidation, and MWCNTs oxidation, respectively. On the other hand, the balanced weight $(82.6$ wt. $\%)$ is due to the residual catalyst. The ratio of SWCNTs to MWCNTs for this sample is about 7.3, which is higher than that for the sample prepared in the presence of Fe.

As shown in the TG analysis (Figure 7(a) and (b)), during the purification of products by acid leaching, most of the remaining $\mathrm{Fe}$ catalyst can be removed. Hence the residual mass can be related to the encapsulated Fe as carbide in CNTs (about 22.6 wt.\%). On the other hand, acid leaching has a lower effect on $\mathrm{Fe}_{0.7} \mathrm{Nb}_{0.1} \mathrm{Zr}_{0.1} \mathrm{Ti}_{0.1}$ in the other sample. This is confirmed by the lower weight losses on the TG diagram (82.6 wt.\% remaining in ashes) [44]. The higher tendency of the sample prepared in the presence of $\mathrm{Fe}_{0.7} \mathrm{Nb}_{0.1} \mathrm{Zr}_{0.1} \mathrm{Ti}_{0.1}$ to form SWCNTs can be related to the microstructure of the metallic catalyst. In this sample, the amorphous structure of the catalyst, on the one hand, induces unordered surface of the metallic catalyst and, on the other hand, provides a smaller nucleation site for the preparation of CNTs. However, in the crystalline catalyst (i.e., Fe), the larger plate acts as a nucleation site for the preparation of CNTs. Consequently, the formation of MWCNTs is preferred in the presence of $\mathrm{Fe}[3]$. As shown in Table 3, the higher stability of the CNTs in the sample prepared by Fe confirms its higher quality than the other sample.

\subsection{Adsorption characteristics of CNTs}

Physical form and the structure of CNTs induce a large surface area about $1315 \mathrm{~m}^{2} / \mathrm{g}^{-1}$, by theoretical approximation, for discreet SWCNTs. However, the measured surface areas of CNTs are significantly lower [53]. The properties of CNTs are strongly related to the impurities, the method of production, debundling of the fibers, surface functionalization, CNT diameter, and the number of walls [53]. Adsorption of nitrogen at $77 \mathrm{~K}$ is a general technique to estimate the Specific Surface Area (SSA) of a material. Nitrogen can be

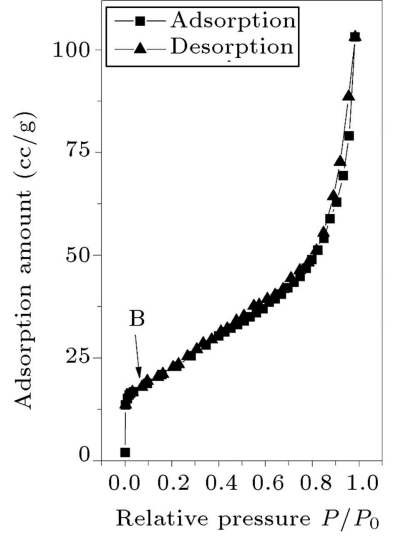

(a)

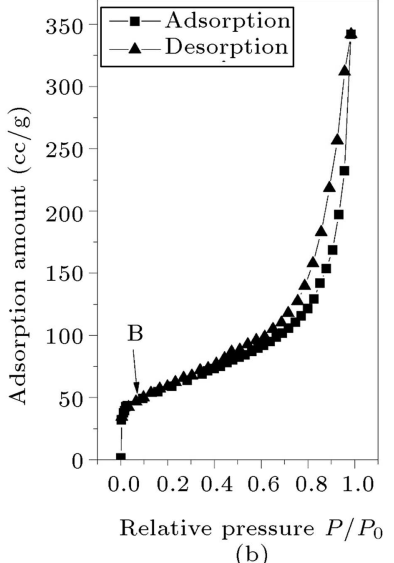

(b)
Figure 8. $\mathrm{N}_{2}$ adsorption isotherms for the Carbon Nanotubes (CNTs) prepared in the presence of (a) Fe and (b) $\mathrm{Fe}_{0.7} \mathrm{Nb}_{0.1} \mathrm{Zr}_{0.1} \mathrm{Ti}_{0.1}$ catalysts.

adsorbed in the prepared CNTs by the curved portion of the outer surface, the groove situation produced by CNTs conjunction, or the other defect sites [31,53]. The inner core of CNTs is another spot for the adsorption of nitrogen. A similar space is provided at the bundle of three or more CNTs. Since the diameter of nitrogen is $3.64 \mathrm{~A}^{\circ}$, i.e. higher than the $3.4 \mathrm{~A}^{\circ}$ space in MWCNTs, its adsorbtion is impossible in the space between the MWCNT layers. According to the literature, the preparation process plays a key role in determining the ratio of the prepared closed to open CNTs. Generally, it is supposed that the prepared CNTs are closed structures unless they undergo further treatment, e.g., milling, to open their ends [53].

Figure 8 shows the isotherms of both samples. In case of Fe as catalyst (Figure 8(a)), the isotherm curve is similar to the behavior of non-porous or macroporous adsorbent [54], indicating the monolayer-multilayer adsorption type of the prepared CNTs. Point B, i.e., the start of the linear section of the isotherm, is a sign of the completion of monolayer coverage and the start of multilayer adsorption. Such observation is confirmed by the low SWCNTs/MWCNTs ratio in this sample. For the sample prepared in the presence of $\mathrm{Fe}_{0.7} \mathrm{Nb}_{0.1} \mathrm{Zr}_{0.1} \mathrm{Ti}_{0.1}$ as a catalyst, as indicated in 
Figure $8(\mathrm{~b})$, the appearance of a hysteresis loop indicates the occurrence of mesoporous capillary condensation. The first section of Figure $8(\mathrm{~b})$ is related to the monolayer-multilayer adsorption. As shown, both samples go through the same path in isotherm curves. Since the sample prepared by $\mathrm{Fe}_{0.7} \mathrm{Nb}_{0.1} \mathrm{Zr}_{0.1} \mathrm{Ti}_{0.1}$ has a higher SWCNTs/MWCNTs ratio than the other one, it can act as a mesoporous material.

SSA is another characteristic of Brunauer Emmett Teller (BET). The SSA of samples prepared in the presence of $\mathrm{Fe}_{0.7} \mathrm{Nb}_{0.1} \mathrm{Zr}_{0.1} \mathrm{Ti}_{0.1}$ and $\mathrm{Fe}$ as catalysts was measured at about $198.31 \mathrm{~m}^{2} / \mathrm{g}$ and $81.14 \mathrm{~m}^{2} / \mathrm{g}$, respectively. While the residual catalyst particles decrease the SSA, the sample prepared in the presence of $\mathrm{Fe}_{0.7} \mathrm{Nb}_{0.1} \mathrm{Zr}_{0.1} \mathrm{Ti}_{0.1}$, which leads to a higher amount of residual catalyst, has a higher amount of SSA due to the higher amount of SWCNTs. It is worth noting that the SWCNTs have higher SSAs than MWCNTs as a consequence of their lower shell and higher surface [53]. It seems that amorphous carbons act as a filling agent and decrease the adsorption potential of the prepared CNTs. Moreover, the amorphous phase diminishes the SSA due to its lower surface area than CNTs, inducing lower adsorption and desorption rate [55].

\section{Conclusion}

In this study, the Carbon Nano-Tubes (CNTs) were prepared by direct milling of hexane as a precursor in the presence of two separate types of metallic catalysts (namely Fe and amorphous $\mathrm{Fe}_{0.7} \mathrm{Nb}_{0.1} \mathrm{Zr}_{0.1} \mathrm{Ti}_{0.1}$ alloy). By considering $\mathrm{I}_{D 1} / \mathrm{I}_{G}$ ratio as a criterion for determining the quality products, Fe appeared as a more appropriate catalyst than $\mathrm{Fe}_{0.7} \mathrm{Nb}_{0.1} \mathrm{Zr}_{0.1} \mathrm{Ti}_{0.1}$ for the preparation of CNTs. However, in terms of purity, the sample that was milled by $\mathrm{Fe}_{0.7} \mathrm{Nb}_{0.1} \mathrm{Zr}_{0.1} \mathrm{Ti}_{0.1}$ alloy was preferred. Also, milling in the presence of $\mathrm{Fe}_{0.7} \mathrm{Nb}_{0.1} \mathrm{Zr}_{0.1} \mathrm{Ti}_{0.1}$ produced more Single-Wall Carbon Nano-Tubes (SWCNTs) than Multi-Wall Carbone Nano-Tubes (MWCNTs), while the opposite was true for the case of Fe. The Brunauer Emmett Teller (BET) surface areas were $198.31 \mathrm{~m}^{2} / \mathrm{g}$ and $81.14 \mathrm{~m}^{2} / \mathrm{g}$ for the CNTs prepared in the presence of $\mathrm{Fe}$ and $\mathrm{Fe}_{0.7} \mathrm{Nb}_{0.1} \mathrm{Zr}_{0.1} \mathrm{Ti}_{0.1}$ as catalysts, respectively. The BET surface area increased with increasing the SWCNTs/MWCNTs ratio. The proposed method appeared as a simple and efficient technique with cheap and easily accessible raw materials to enhance the adsorption properties. Hence, it can be proposed as a good option in the preparation of CNTs for such utilities.

\section{References}

1. Iijima, S. "Helical microtubules of graphitic carbon", Nature, 354, pp. 56-58 (1991).

2. Terrones, M. "Science and technology of the twenty- first century: synthesis, properties, and applications of carbon nanotubes", Annual Review of Materials Research, 33, pp. 419-501 (2003).

3. Wang, R., Xie, L., Hameed, S., et al. "Mechanisms and applications of carbon nanotubes in terahertz devices: A review", Carbon, 132, pp. 42-58 (2018).

4. Hou, P.-X., Liu, C., and Cheng, H.-M. "Purification of carbon nanotubes", Carbon, 46, pp. 2003-2025 (2008).

5. Krueger, A., Carbon materials and nanotechnology, John Wiley \& Sons (2010).

6. Fazelirad, H., Ranjbar, M., Taher, M.A., et al. "Preparation of magnetic multi-walled carbon nanotubes for an efficient adsorption and spectrophotometric determination of amoxicillin", Journal of Industrial and Engineering Chemistry, 21, pp. 889-892 (2015).

7. Sun, L., Wang, X., Wang, Y., et al. "Roles of carbon nanotubes in novel energy storage devices", Carbon, 122, pp. 462-474 (2017).

8. Rashad, A.M. "Effect of carbon nanotubes (CNTs) on the properties of traditional cementitious materials", Construction and Building Materials, 153, pp. 81-101 (2017)

9. Rahimian-Koloor, S.M., Hashemianzadeh, S.M., and Shokrieh, M.M. "Effect of CNT structural defects on the mechanical properties of CNT/Epoxy nanocomposite", Physica B: Condensed Matter, 540, pp. 16-25 (2018).

10. Mirmohammadi, S.A., Sadjadi, S., and BahriLaleh, N. "10-electrical and electromagnetic properties of CNT/polymer composites", Carbon NanotubeReinforced Polymers: From Nanoscale to Macroscale, pp. 233-258, Elsevier (2018).

11. Wang, Y., Li, D., Sun, W., et al. "Synthesis and field electron emission properties of multi-walled carbon nanotube films directly grown on catalytic stainless steel substrate", Vacuum, 149, pp. 195-199 (2018).

12. Gao, S., Liu, H., Xu, L., et al. "Hydrogen storage properties of nano-CoB/CNTs catalyzed MgH2", Journal of Alloys and Compounds, 735, pp. 635-642 (2018).

13. Liu, X.Q., Li, C.J., Yi, J.H., et al. "Enhancing the interface bonding in carbon nanotubes reinforced $\mathrm{Al}$ matrix composites by the in situ formation of TiAl3 and TiC", Journal of Alloys and Compounds, 765, pp. 98-105 (2018).

14. Yang, P., You, X., Yi, J., et al. "Influence of dispersion state of carbon nanotubes on electrical conductivity of copper matrix composites", Journal of Alloys and Compounds, 752, pp. 376-380 (2018).

15. Liao, J. and Tan, M.-J. "Mixing of carbon nanotubes (CNTs) and aluminum powder for powder metallurgy use", Powder Technology, 208, pp. 42-48 (2011).

16. Barzegar-Bafrooei, H. and Ebadzadeh, T. "Synthesis of nanocomposite powders of $\gamma$-alumina-carbon nanotube by sol-gel method", Advanced Powder Technology, 22, pp. 366-369 (2011). 
17. Hosseini, A., Ghoreyshi, A.A., Pirzadeh, K., et al. "Enhancement of hydrogen storage on multi-walled carbon nanotube through $\mathrm{KOH}$ activation and nickel nanoparticle deposition", Scientia Iranica, 24, pp. $1230-1240$ (2017).

18. Yousefzadeh, M., Amani-Tehran, M., Latifi, M., et al. "Morphology and mechanical properties of polyacrylonitrile/multi-walled carbon nanotube (PAN/

MWNTs) nanocomposite electrospun nanofibers", Scientia Iranica, 17, pp. 60-65 (2010).

19. Laplaze, D., Bernier, P., Maser, W.K., et al. "Carbon nanotubes: The solar approach", Carbon, 36, pp. 685688 (1998).

20. Su, Y. and Zhang, Y. "Carbon nanomaterials synthesized by arc discharge hot plasma", Carbon, 83, pp. 90-99 (2015).

21. Amans, D., Diouf, M., Lam, J., et al. "Origin of the nano-carbon allotropes in pulsed laser ablation in liquids synthesis", Journal of Colloid and Interface Science, 489, pp. 114-125 (2017).

22. Yilmaz, M., Raina, S., Hsu, S.H., et al. "Growing micropatterned CNT arrays on aluminum substrates using hot-filament CVD process", Materials Letters, 209, pp. 376-378 (2017).

23. Huang, T., Fang, H., Mao, S., et al. "In-situ synthesized TiC@CNT as high-performance catalysts for oxygen reduction reaction", Carbon, 126, pp. 566-573 (2018).

24. Guler, O. and Evin, E. "Carbon nanotubes formation by short-time ball milling and annealing of graphite", Optoelectronics and Advanced Materials-Rapid Communications, 6, pp. 183-187 (2012).

25. Chen, Y., Fitz Gerald, J., Chadderton L., et al. "Investigation of nanoporous carbon powders produced by high energy ball milling and formation of carbon nanotubes during subsequent annealing", Journal of Metastable and Nanocrystalline Materials, 2(6), pp. 375-380 (1999).

26. Chen, Y., Conway, M., Gerald, J.F., et al. "The nucleation and growth of carbon nanotubes in a mechanothermal process", Carbon, 42, pp. 1543-1548 (2004).

27. Pierard, N., Fonseca, A., Konya, Z., et al. "Production of short carbon nanotubes with open tips by ball milling", Chemical Physics Letters, 335, pp. 18 (2001).

28. Jeong, S.W., Son, S.Y., and Lee, D.H. "Synthesis of multi-walled carbon nanotubes using $\mathrm{Co}-\mathrm{Fe}-$ $\mathrm{Mo} / \mathrm{A} 12 \mathrm{O} 3$ catalytic powders in a fluidized bed reactor", Advanced Powder Technology, 21, pp. 93-99 (2010).

29. Sano, N., Kinugasa, M., Otsuki, F., et al. "Gas sensor using single-wall carbon nanohorns", Advanced Powder Technology, 18, pp. 455-466 (2007).
30. Ghosh, S. and Padmanabhan, V. "Adsorption of hydrogen on single-walled carbon nanotubes with defects", Diamond and Related Materials, 59, pp. 47-53 (2015).

31. Chen, M., Yu, H.-W., Chen, J.-H., et al. "Effect of purification treatment on adsorption characteristics of carbon nanotubes", Diamond and Related Materials, 16, pp. 1110-1115 (2007).

32. Liu, F., Zhang, X., Cheng, J., et al. "Preparation of short carbon nanotubes by mechanical ball milling and their hydrogen adsorption behavior", Carbon, 41, pp. 2527-2532 (2003).

33. Pierard, N., Fonseca, A., Colomer, J.F., et al. "Ball milling effect on the structure of single-wall carbon nanotubes", Carbon, 42, pp. 1691-1697 (2004).

34. Khayati, G.R. and Janghorban, K. "The nanostructure evolution of Ag powder synthesized by high energy ball milling", Advanced Powder Technology, 23, pp. 393397 (2012).

35. Zhong, Y., Chaudhary, V., Tan, X., et al. "Kinetic study of the mechanochemical synthesis of $\mathrm{Nd} 2$ (Fe, Co) 14B hard magnetic nanoparticles", Journal of Alloys and Compounds, 747, pp. 755-763 (2018).

36. Routray, K.L., Saha, S., and Behera, D. "Effect of CNTs blending on the structural, dielectric and magnetic properties of nanosized cobalt ferrite", Materials Science and Engineering: B, 226, pp. 199-205 (2017).

37. Khazaei Feizabad, M.H., Sharafi, S., Khayati, G.R., et al. "Effect of process control agent on the structural and magnetic properties of nano/amorphous $\mathrm{Fe}_{0.7} \mathrm{Nb}_{0.1} \mathrm{Zr}_{0.1} \mathrm{Ti}_{0.1}$ powders prepared by high energy ball milling", Journal of Magnetism and Magnetic Materials, 449, pp. 297-303 (2018).

38. Suryanarayana, C., Mechanical Alloying and Milling, CRC Press (2004).

39. Mazzucco, S., Wang, Y., Tanase, M., et al. "Direct evidence of active and inactive phases of Fe catalyst nanoparticles for carbon nanotube formation", Journal of Catalysis, 319, pp. 54-60 (2014).

40. Tsui, F. and Ryan, P. "Self-organization of carbide superlattice and nucleation of carbon nanotubes", Journal of Nanoscience and Nanotechnology, 3, pp. 529-534 (2003).

41. Jia, X. and Wei, F. "Advances in production and applications of carbon nanotubes", Topics in Current Chemistry, 375, p. 18 (2017).

42. Kumar, M. "Carbon nanotube synthesis and growth mechanism", Carbon Nanotubes-Synthesis, Characterization, Applications, pp. 147-170 (2011).

43. Antunes, E.F., Lobo, A.O., Corat, E.J., et al. "Comparative study of first- and second-order Raman spectra of MWCNT at visible and infrared laser excitation", Carbon, 44, pp. 2202-2211 (2006).

44. Lehman, J.H., Terrones, M., Mansfield, E., et al. "Evaluating the characteristics of multiwall carbon nanotubes", Carbon, 49, pp. 2581-2602 (2011). 
45. Santangelo, S., Messina, G., Donato, M., et al. "Lowfrequency Raman study of hollow multiwalled nanotubes grown by Fe-catalyzed chemical vapor deposition", Journal of Applied Physics, 100, p. 104311 (2006).

46. Donato, M., Messina, G., Santangelo, S., et al. "Aid of raman spectroscopy in diagnostics of MWCNT synthesised by Fe-catalysed CVD", Journal of Physics: Conference Series, 61(1), pp. 931-935 (2007).

47. DiLeo, R.A., Landi, B.J., and Raffaelle, R.P. "Purity assessment of multiwalled carbon nanotubes by Raman spectroscopy", Journal of Applied Physics, 101, p. 064307 (2007).

48. Sadezky, A., Muckenhuber, H., Grothe, H., et al. "Raman microspectroscopy of soot and related carbonaceous materials: Spectral analysis and structural information", Carbon, 43, pp. 1731-1742 (2005).

49. Dresselhaus, M.S., Dresselhaus, G., Saito, R., et al. "Raman spectroscopy of carbon nanotubes", Physics Reports, 409, pp. 47-99 (2005).

50. Khazaei Feizabad, M.H., Sharafi, S., Khayati, G.R., et al. "Modeling of stress relaxation kinetics of amorphous $\mathrm{Fe}_{0.7} \mathrm{Nb}_{0.1} \mathrm{Zr}_{0.1} \mathrm{Ti}_{0.1}$ alloy powder: A novel approach based on differential thermal analysis", Powder Technology, 336, pp. 441-448 (2018).

51. Khazaei Feizabad, M.H., Khayati, G.R., Sharafi, S., et al. "Improvement of soft magnetic properties of $\mathrm{Fe}_{0.7} \mathrm{Nb}_{0.1} \mathrm{Zr}_{0.1} \mathrm{Ti}_{0.1}$ amorphous alloy: A kinetic study approach", Journal of Non-Crystalline Solids, 493, pp. 11-19 (2018).

52. Khazaei Feizabad, M.H., Khayati, G.R., and Minouei, H. "A kinetic study approach for in-situ preparation of amorphous $\mathrm{Ni}$ based nanocomposite reinforced by nanocrystalline Ni-Ti shape memory alloy", Journal of Non-Crystalline Solids, 524, p. 119652 (2019).

53. Birch, M.E., Ruda-Eberenz, T.A., Chai, M., et al. "Properties that influence the specific surface areas of carbon nanotubes and nanofibers", Annals of Occupational Hygiene, 57, pp. 1148-1166 (2013).
54. Sing, K.S. "Reporting physisorption data for gas/solid systems with special reference to the determination of surface area and porosity (Recommendations 1984)", Pure and Applied Chemistry, 57, pp. 603-619 (1985).

55. Maryam, M., Suriani, A., Shamsudin, M.S., et al. "BET analysis on carbon nanotubes: Comparison between single and double stage thermal CVD method", Advanced Materials Research, 626, pp. 289293 (2013).

\section{Biographies}

Mohammad Hossein Khazaei Feizabad received his BSc with honors in Materials Science from Sistan \& Baluchestan University of Zahedan, MSc in Materials Science Engineering from the Department of Materials Science and Engineering at Shiraz University, and PhD in Nano Materials Engineering from Shahid Bahonar University of Kerman, Kerman, Iran, in 2019. He has published more than 15 scientific papers in the field of synthesis and characterization of nanostructure materials.

Gholam Reza Khayati is currently a faculty member of Materials Science and Engineering at Shahid Bahonar University of Kerman. He received his BSc with honors in Materials Science from Shahid Bahonar University of Kerman in 2004, MSc in Materials Science and Engineering from the Department of Materials Science \& Engineering at University of Tehran, and $\mathrm{PhD}$ in Materials Science from Shiraz University, Iran. He has published more than 40 scientific papers in the field of synthesis and characterization of nanostructure materials.

Sorayya Pouresterabadi received her BSc and MSc degrees in Materials Science Engineering from the Department of Materials Science \& Engineering at Shahid Bahonar University of Kerman, Kerman, Iran. 